\title{
The Impact of Export Capabilities and Competitive Advantage on SME's International Performance
}

\author{
Donn Sandi ${ }^{1}$, Budi Susanto ${ }^{2}$, Rismi Juliadi ${ }^{3}$ \\ \{donn.rithalna@student.umn.ac.id ${ }^{1}$, bsusanto@umn.ac.id², rismi.juliadi@umn.ac.id ${ }^{3}$ \} \\ Department of Technology Management, Universitas Multimedia Nusantara
}

\begin{abstract}
Small and medium businesses (SMEs) have a significant impact on the Indonesian economy, both in terms of GDP and jobs. This research aims to examine the impact of export capabilities and competitive advantage to SMEs' international performance. Background Problems: There is still an inconsistency among previous research on capabilities-competitive advantage-performance relations. Objective: This study would determine which capabilities have the greatest influence on a SME's international success, as well as whether competitive advantage plays a role in mediating the relationship between capabilities and performance. Research Methods: This research uses the quantitative method with 55 respondents from all over Indonesia, and then the analysis uses PLS-SEM with SmartPLS software. Findings/Results: The product innovation does not influence the competitive advantage. Market intelligence, marketing communication, and pricing influence the competitive advantage. Also, the competitive advantage influences international performance but does not have the mediate role between the export capabilities and international performance. Conclusion: Between export capabilities: market communication, pricing, and market intelligence are the most impactful to SMEs' international performance. SMEs leaders should focus on the resources on those capabilities, while government and academic researchers still support on product innovation.
\end{abstract}

Keywords: export capabilities ,international performance, competitive advantage, market intelligence, marketing communication, pricing capability, small and medium enterprises, product innovation

\section{Introduction}

Small and medium businesses (SMEs) play an important role in the Indonesian economy. SMEs account for 60.34 percent of Indonesia's GDP. SMEs can absorb around 96 percent of the workforce in Indonesia [1]. Only less than 5\% of Indonesian SMEs already export to the international market [2]. Asian Development Bank has measured a national SMEs' international performance by a ratio of SME's export revenue and total export revenue. By this parameter, Indonesia addresses a low position, below Thailand, Philippines, and Malaysia [3].

Since early 2020, the world has impacted almost every sector by the pandemic condition because of Covid-19. Indonesian SMEs also experienced a problematic economic situation; competition in the domestic market became more challenging, and it also has proven in the global market. Then we studied the literature and the results of previous studies regarding the variables of international performance, competitive advantage, and strong export capabilities. Many previous studies have examined the effect of capabilities on performance, but only a few have examined the effect of capabilities on competitive advantage. Previous 
studies regarding the effect of export capabilities on the international performance of a company have obtained mixed results and are less clear [4].

Because competitive advantage and performance are two distinct concepts, and most previous studies have focused solely on the impact of capabilities on performance, more research into the impact of capabilities on competitive advantage is required [5]. To improve Indonesian SMEs' international performance, strategic steps are needed based on the analysis of the most influential variables. However, it turns out that based on the results of previous studies on international performance, the results are still very mixed, meaning which export capabilities variable has the most significant effect is still unclear. Are different results due to the mediator variable between export capabilities and international performance? Is the mediator variable a competitive advantage?

To answer the question in the formulation of the problem, the researcher intends to measure the magnitude of the influence of export capabilities factors on the competitive advantage of an SME and to test whether competitive advantage serves as a mediator between export capabilities and international performance.

Researchers hope that this study's results can contribute in the context of the existence of gaps in the theory of the export capabilities - competitive advantage - international performance variable. Moreover, it is also useful as a managerial recommendation for SME practitioners who carry out the export process, namely that they can focus on the export capability that has the most significant impact on international performance. This study's results can also be useful for the government focusing on which factors are most appropriate in providing support to SMEs to be able to improve their international performance within limited resources.

\section{Literature Review}

An exporting firm must have specific benefits that must always be competitive to be competitive in the global marketplace [6]. A firm's capabilities are complicated, according to the resource-based view (RBV) [7]. Unique configurations and interrelationships of the company's sources shape and blend capabilities, which can be difficult to replicate [8]. In other words, while capabilities are long-lasting, unique, and difficult to duplicate, they can provide a competitive advantage.

Weerawardena [9] studied marketing capability and competitive advantage function using 324 companies. According to Weerawardena [9], marketing capability and competitive advantage are linked. Zou [10] investigated the relationship between four capabilities and export performance, finding that distribution, conversation, and product improvement abilities are all positively related to international performance, but pricing capability is not. Kamboj [11] looked into the link between marketing capability, competitive advantage, and overall performance. The role of competitive advantage as a mediating factor in the relationships between entrepreneurial orientation, intangible sources, and absorptive abilities was investigated by Rua [12]. Even though research has improved in recent decades, more research is needed to fully comprehend the components of competitive advantage and the mediating role of competitive advantage on specific types of abilities.

Financial and strategic performance can be used to assess SMEs' international performance [13]. Control characteristics, export strategy, advertising blend, export information, export knowledge, business relationships, and market characteristics were found in Beleska- Spasova's [4] review of the literature on the elements of international performance. Pham. [14] discovered that market intelligence, product innovation, pricing capability, and 
marketing communication are all good family members when it comes to international performance.

We hypothesized four essential competencies that could aid the development of competitive advantage for exporting SMEs and mediate the relationship between these capabilities and SMEs' international performance, based entirely on the findings of Pham[14]. The researchers want to look into the key components of a competitive advantage that affect SMEs' international performance, and see if the competitive advantage acts as a link between these capabilities and SMEs' international performance.

\subsection{Capabilities and Competitive Advantage Relation}

In accordance with the findings of George S. Day [15], market intelligence provides information on competition, consumers, and commercial enterprise participants. It allows companies to achieve a competitive edge by leveraging business opportunities. The functionality of market intelligence can also improve firm success through the use of a strategic edge in market statistics, corporate research and intellectual capital [16]. In terms of foreign market conditions, exporting SMEs have restricted expertise. In such cases, market intelligence can also have an enormous effect on SMEs' international success, allowing them to build aggressive advantages in order to face challenges through internationalization [17]. It is proposed the following hypothesis:

Hypothesis 1. The relationship between the SMEs business intelligence and their competitive advantage is positive.

The functionality of product innovation reflects the ability of a company to increase, adapt or innovate the product range if it wishes to satisfy customer demands [10]. The capacity for product creativity can be appreciated and unusual, and could thus provide a competitive advantage when allowing a company to respond to customers' converting wishes [18].

Hypothesis 2. The relationship between Product Innovation and competitive advantage in SMEs is positive.

Capacity in pricing means an enterprise's ability to determine cost based on balanced expenditure attention, opposition and buyer preferences [19]. Few pricing studies show that companies offering greater pricing versatility will pay the best price for bids. Most people found that the pricing capabilities of an organization result in a strategic advantage associated with reduced expenditures as compared to its competitors [20].

Hypothesis 3. The relationship between pricing capacity and SMEs competitive advantage is positive.

The ability of an organization to develop, manage and disclose its marketing communications activities [14] is marketing communication capacity. The ability, through a successful advertisement and marketing programme, to distinguish between product services and rivals will add value. The ability to market contact allows companies to become more conscious, communicate and represent their markets, improved business performance [21]. The ability to communicate with markets can also allow companies to benefit from competitive advantages, particularly if exports can balance their domestic and international conversations packages [9]. The following theories include the following:

Hypothesis 4. There is a positive relationship between the marketing capacity and competitive advantage. 


\subsection{Competitive Advantage and International Performance Relation}

Competitive advantage refers to the unmatched price of services or products that enables a business to outperform its competitors [22]. Competitive advantage can be achieved through the provision of low-cost or differentiated services or products [5]. The majority of prior research concludes that a company's competitive advantage is related to its international performance [12]. According to Chelliah [23], competitive advantage has little effect on international performance. Additional research confirming the relationship between competitive advantage and international performance, particularly for SMEs, is desired. It is proposed the following hypothesis:

Hypothesis 5. There is a positive relationship between the SMEs competitive advantage and their international performance.

Despite research on global performance factors, combination outcomes related to the effect of talents on a company's performance have been acquired [4]. Recent research indicates that one possible explanation for the inconsistent findings in the capability-performance relationship is a situation in which mediator variables with a competitive advantage are overlooked [12]. Competitive advantage, we argue, mediates the relationship between SME export capabilities and international performance. These expectations are expressed in the following hypotheses:

Hypothesis 6. Competitive advantage acts as a mediating factor in the relationship between market intelligence and international performance of SMEs.

Hypothesis 7. Competitive advantage acts as a mediating factor in the relationship between product innovation and international performance of SMEs.

Hypothesis 8. Competitive advantage acts as a mediating factor in the relationship between pricing capability and international performance of SMEs.

Hypothesis 9. Competitive advantage acts as a moderating factor in the relationship between marketing communication and the international performance of SMEs.

\section{Research Methodology}

\subsection{Data}

This research's object is export capabilities, competitive advantage and international performance of SMEs in Indonesia who carry out export activities, their success in carrying out exports to international markets, and their relation to the research framework's variables. The research subject is the owner or export manager (person who understands the SMEs' export activity). A complete of 60 have been identified for participation. The data generation was conducted in a questionnaire. First, thirty SMEs have been randomly decided on to pretest the questionnaires. Primarily based on the responses within the pretest, minor modifications had been made to the questionnaire for the next phase of statistics collection. Records turned into accrued in April-July 2020. Overall, a very last dataset of 55 valid cases was received. 


\subsection{Measures of Variables}

For the competitive advantage variable, researchers used 5 indicators in Kaleka \& Morgan [24] study. For international performance variables, researchers used 4 indicators from the research of Falahat [13]. For the variables of market intelligence, product innovation, pricing and marketing communication, researchers used the indicators from the research of Pham. [14].

The researchers collected primary data by distributing questionnaires to respondents according to the sample criteria above. The questionnaire questions consist of respondent profile questions, screening questions (to ensure that the research subject is relevant to be sampled) and indicator questions with a Likert scale of 1-5. Then the questionnaire was distributed in an online survey via Google Form to the respective respondents.

\subsection{Measurement Model}

The researchers dimensioned, validated, and tested the structural model using Structural Equation Modeling (SEM). We employ the Partial Least Squares (PLS) SEM technique, which is implemented in the SmartPLS 3.3.2 software program [25]. The composite reliability (CR) and average variance extracted (AVE) indices were used to determine the reliability of measures in this study. Both were greater than the assessment criteria for all measures, namely 0.7 for the CR index and 0.5 for the AVE index [26]. All values were within the recommended range, indicating reliability and convergent validity. To determine discriminant validity [27], the square root of the AVE for each construct must be greater than the absolute value of inter-assemble correlations. All constructs met this criterion, indicating that the objects have a greater degree of significant variance with their own constructs than with other constructs. The Heterotrait-Monotrait Correlation Ratio (HMTM) was used to assess discriminant validity [28]. A cost of HTMT greater than 0.85 indicates a problem with discriminant validity. All constructs had HTMT values less than 0.85 . In conclusion, those tests indicated that discriminant validity does not pose a significant risk in our observation.

\section{Empirical Results}

This paper uses PLS SEM to test all of the hypotheses. Greater in particular, we implemented entire bootstrapping, putting with 500 subsamples and a two-tailed test for speculation trying out. As shown in Table 1, market intelligence, marketing communication and pricing capability are undoubtedly associated with a competitive advantage, supporting hypotheses $\mathrm{H} 1, \mathrm{H} 3$, and $\mathrm{H} 4$. Competitive advantage was positively related to SMEs' international performance, for this reason, hypothesis H5 turned into showed. Hypothesis H2 did no longer discover guide, indicating a non-sizeable relation between product innovation and competitive advantage. 


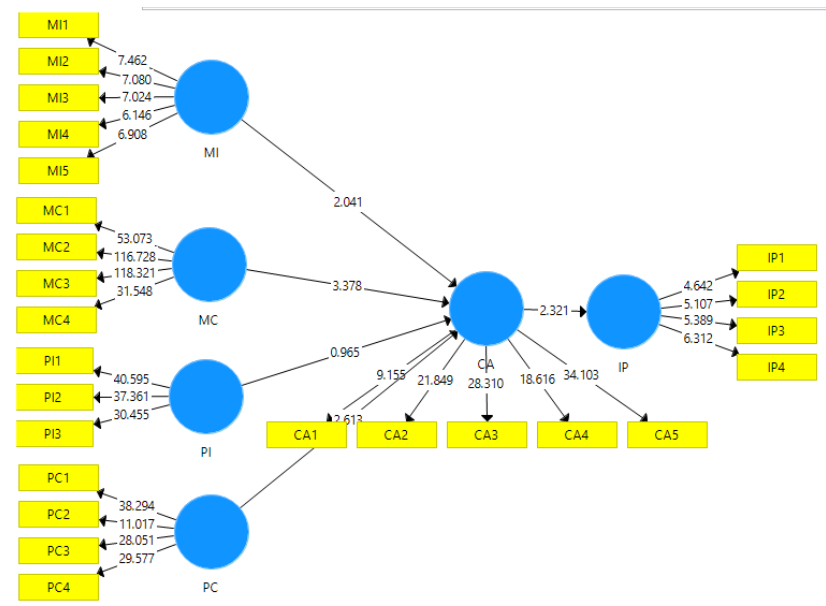

Figure 1. Research Model and Result

MI: Market Intelligence; MC: Marketing Communication; PI: Product Innovation PC: Pricing Capability; CA: Competitive Advantage; IP: International Performance

Table 1. Hypothesis Test Result

\begin{tabular}{|l|r|r|r|r|r|}
\hline & Original Sampl & Sample Mean (M & Standard Deviat & Statistics (|O & P Values \\
\hline CA $\rightarrow$ IP & 0.281 & 0.310 & 0.130 & 2.168 & 0.031 \\
\hline MC $>$ CA & 0.621 & 0.610 & 0.163 & 3.819 & 0.000 \\
\hline MI $\rightarrow$ CA & -0.311 & -0.271 & 0.154 & 2.016 & 0.044 \\
\hline PC $>$ CA & 0.416 & 0.417 & 0.156 & 2.669 & 0.008 \\
\hline PI $>$ CA & -0.128 & -0.130 & 0.116 & 1.104 & 0.270 \\
\hline
\end{tabular}

Table 2. Mediating Test Result

\begin{tabular}{|l|r|r|r|r|r|}
\hline & Original Sampl & Sample Mean (M & Standard Deviat & Ttatistics (|O & P Values \\
\hline $\mathrm{MC} \rightarrow$ CA $\rightarrow$ I & 0.175 & 0.196 & 0.096 & 1.821 & 0.069 \\
\hline $\mathrm{MI} \rightarrow$ CA $\rightarrow$ If & -0.087 & -0.085 & 0.061 & 1.443 & 0.150 \\
\hline $\mathrm{PC} \rightarrow$ CA $\rightarrow$ I & 0.117 & 0.130 & 0.079 & 1.475 & 0.141 \\
\hline $\mathrm{PI} \rightarrow$ CA $\rightarrow$ IP & -0.036 & -0.043 & 0.041 & 0.874 & 0.382 \\
\hline
\end{tabular}

\section{Conclusion, Limitation and Future Research}

It turns out that from the test results of the hypotheses, the export capabilities that affect competitive advantage are market intelligence, pricing, and marketing communication. Meanwhile, product innovation has no positive effect on competitive advantage. The researcher concludes that this may be different from the previous studies because in the Indonesian context, SMEs prioritize prices and services over product innovation.

The results of the mediation test show that it turns out that competitive advantage does not act as a mediator with export capabilities (market intelligence, product innovation, pricing and marketing communication) with international performance. According to the researchers' analysis, the different results from previous studies were probably due to respondents' 
limitations. First, in terms of the number, which is only 55 SMEs, and the industrial sector is still limited with the majority of the low-tech medical equipment industry. Researchers note that this industrial sector allows conditions in which SME has a high competitive advantage in the local market but low in the international market.

For this reason, the researchers would like to suggest that further research should be carried out with respondents who are more diverse in the industrial sector and with a larger number of respondents. Maybe the results of the hypothesis test might show different results. Or it could be done in combination with qualitative research, for example conducting in-depth interviews with one of the SMEs with the most significant amount/value of exports.

The researchers also want to provide managerial advice to decision-makers in Indonesian SMEs to prioritize the capabilities of market intelligence, pricing, and marketing communication. Because based on the test before, these three capabilities have the most influence on SMEs' competitive advantage.

The majority of SMEs certainly have limited resources to develop market intelligence, pricing, and marketing communication capabilities. The government, in this case, the Ministry of Cooperatives and SMEs, needs to increase its support in the form of, for example, free training, providing a platform with a global market, access to funding, others. In addition to the existing ones, such as providing booths at SMEs exhibitions abroad or existing mentoring programs. It is suggested, these recommendations can be useful for SMEs struggling to improve their international performance by using more efficient and targeted resources according to the most critical priorities. Hopefully, the efficient and effective deployment of resources will soon enable SMEs in Indonesia to rise above the obstacles caused by the Covid-19 pandemic, which is still unclear when the vaccine can start to be used.

\section{References}

[1] Badan Pusat Statistik, "Indonesia 2019 Outlook,” Lap. Perekon. Indones. 2019, vol. 04, no. 01, 2019.

[2] Depkop, "Perkembangan Data Usaha Mikro, Kecil , Menengah Dan Usaha Besar," Www.Depkop.Go.Id, vol. 2000, no. 1, p. 1, 2018.

[3] Asia Development Bank, "Small and Medium-Sized Enterprises in Asia and the Pacific: Context and Issues," pp. 1-10, 2018, [Online]. Available: https://www.adb.org/sites/default/files/linked-documents/A-SME-Context-andIssues.pdf.

[4] E. Beleska-Spasova, "Determinants and Measures of Export Performance Comprehensive Literature Review," Jcebi, vol. 1, no. 1, pp. 63-74, 2014.

[5] A. Kaleka, "Resources and capabilities driving competitive advantage in export markets: Guidelines for industrial exporters," Ind. Mark. Manag., vol. 31, no. 3, pp. 273-283, 2002, doi: 10.1016/S0019-8501(00)00148-6.

[6] T. Lee and H. M. Liu, "How do Firms with Management Ability Promote Competitive Advantages? An Integrated Model from Entrepreneurial Strategy Making and Internal Resources,” Entrep. Res. J., vol. 8, no. 2, pp. 1-15, 2018, doi: 10.1515/erj-2017-0071.

[7] J. Barney, "Firm Resources and Sustained Competitive Advantage," J. Manage., vol. 17, no. 1, pp. 99-120, 1991, doi: 10.1177/014920639101700108.

[8] R. M. Grant, The resource-based theory of competitive advantage: Implications for strategy formulation, vol. 33, no. 3. Butterworth-Heinemann, 2009.

[9] J. Weerawardena, "The role of marketing capability in innovation-based competitive 
strategy," J. Strateg. Mark., vol. 11, no. 1, pp. 15-35, 2003, doi: 10.1080/0965254032000096766.

[10] S. Zou, E. Fang, and S. Zhao, "The Effect of Export Marketing Capabilities on Export Performance: An Investigation of Chinese Exporters," J. Int. Mark., vol. 11, no. 4, pp. 32-55, 2003, doi: 10.1509/jimk.11.4.32.20145.

[11] S. Kamboj, P. Goyal, and Z. Rahman, "A Resource-Based View on Marketing Capability, Operations Capability and Financial Performance: An Empirical Examination of Mediating Role," Procedia - Soc. Behav. Sci., vol. 189, pp. 406-415, 2015, doi: 10.1016/j.sbspro.2015.03.201.

[12] O. Rua, A. França, and R. Fernández Ortiz, "Key drivers of SMEs export performance: the mediating effect of competitive advantage," J. Knowl. Manag., vol. 22, no. 2, pp. 257-279, 2018, doi: 10.1108/JKM-07-2017-0267.

[13] M. Falahat, G. Knight, and I. Alon, "Orientations and capabilities of born global firms from emerging markets," Int. Mark. Rev., vol. 35, no. 6, pp. 936957, 2018, doi: 10.1108/IMR-01-2017-0021.

[14] T. S. H. Pham, L. Le Monkhouse, and B. R. Barnes, "The influence of relational capability and marketing capabilities on the export performance of emerging market firms," Int. Mark. Rev., vol. 34, no. 5, pp. 606-628, 2017, doi: 10.1108/IMR-07-2014-0235.

[15] George S.Day, "The Capabilities of Market-Driven.pdf," J. Mark., vol. 58, pp. 37-52, 1994.

[16] R. Colomo-Palacios, E. Fernandes, P. Soto-Acosta, and M. Sabbagh, "Software product evolution for Intellectual Capital Management: The case of Meta4 PeopleNet," Int. J. Inf. Manage., vol. 31, no. 4, pp. 395-399, 2011, doi: 10.1016/j.ijinfomgt.2011.04.001.

[17] F. Evangelista and L. Mac, "The influence of experience and deliberate learning on SME export performance," Int. J. Entrep. Behav. Res., vol. 22, no. 6, pp. 860-879, 2016, doi: 10.1108/IJEBR-12-2015-0300.

[18] Y. Yang and X. F. Ju, "Entrepreneurial Orientation and Firm Performance: Is Product Quality a Missing Link?," Entrep. Res. J., vol. 8, no. 1, pp. 1-13, 2017, doi: 10.1515/erj-2017-0091.

[19] S. Dutta, M. J. Zbaracki, and M. Bergen, "Pricing process as a capability: A resource-based perspective," Strateg. Manag. J., vol. 24, no. 7, pp. 615-630, 2003, doi: $10.1002 / \mathrm{smj} .323$.

[20] D. W. Vorhies and N. A. Morgan, "Capabilities for Sustainable Competitive Advantage," J. Mark., vol. 69, no. January, pp. 80-94, 2005.

[21] S. Hao and M. Song, "Technology-driven strategy and firm performance: Are strategic capabilities missing links?," J. Bus. Res., vol. 69, no. 2, pp. 751-759, 2016, doi: 10.1016/j.jbusres.2015.07.043.

[22] M. E. Porter, "Competitive strategy: Creating and sustaining superior performance," Creat. Sustain. Compet. Advant., 1985, doi: 10.1007/978-3319-54540-0.

[23] S. Chelliah, M. Sulaiman, and S. Pandian, "The Determinants of Internationalization of Small and Medium Enterprises ( Smes ): A Case in 
Malaysia," World Appl. Sci. J., vol. 10, no. 10, pp. 1202-1215, 2010.

[24] A. Kaleka and N. A. Morgan, "Which competitive advantage (s)? Competitive advantage-market performance relationships in international markets," J. Int. Mark., vol. 25, no. 4, pp. 25-49, 2017, doi: 10.1509/jim.16.0058.

[25] C. M. Ringle, S. Wende, and J. M. Becker, "Smart PLS 3," SmartPLS GmbH, http://www.smartpls.com. 2015.

[26] M. Hair, J. F., Hult, G. T. M., Ringle, C. M., \& Sarstedt, "A Primer on Partial Least Squares Structural Equation Modeling (PLS-SEM). Thousand Oaks," Sage, 2013.

[27] C. Fornell and D. F. Larcker, "Evaluating Structural Equation Models with Unobservable Variables and Measurement Error," J. Mark. Res., vol. 18, no. 1, p. 39, 1981, doi: 10.2307/3151312.

[28] J. Henseler, C. M. Ringle, and M. Sarstedt, "A new criterion for assessing discriminant validity in variance-based structural equation modeling," J. Acad. Mark. Sci., vol. 43, no. 1, pp. 115-135, 2014, doi: 10.1007/s11747-014-04038 